\title{
Examining Physical Space, Leadership Inheritance, and "Authentic" Community Engagement through Co-Constructed Autoethnography
}

\author{
Claire Ramsey ${ }^{1}$ and Allison Ricket \\ Ohio University, USA
}

\begin{abstract}
Emerging educational administration leaders must navigate pre-established terrain to affect transformational change. However, an educational organization's pre-existing, bureaucratic climate, culture, and structure can create obstacles for emerging leaders in rural Appalachian school systems. This issue is further complicated for emerging female leaders in rural areas. Therefore, it is important to understand how emerging educational leaders negotiate and create meaningful change in an already established system where leaders in power have a vested interest in preserving the status quo. Through their own, co-constructed, autoethnographic experiences Claire and Allison explore the research questions: To what extent did an existing community-oriented group embody Block's (2018) Community: The Structure of Belonging concepts and methodologies? Where are opportunities for transformation within the preexisting structure of the BAC? The process of understanding these research questions presented Claire and Allison with an opportunity to foster the transformative growth of their educational leadership identities. This qualitative approach encourages Claire and Allison to explore the intersectionalities of their roles within their school-community. The findings yield three prevailing themes: physical space reveals paradigm, inheritance of leadership, and "authentic" community engagement. This study aims to be informative for educational administration leaders, policy makers, and BAC stakeholders who desire to understand that Claire and Allison's experiences, though not generalizable, have transferable qualities and assist in understanding similar situations which occur in public, educational organizations.
\end{abstract}

KEYWORDS: “Authentic" Community Engagement, Co-Constructed Autoethnography, Educational Administration, Leadership Inheritance.

Educational leaders must, at times, make decisions that do not align with our leadership style or pedagogical ideology. As such, new administrative interns must understand how changes might be made despite an organization's pre-existing climate, culture, and structure. We are emerging educational administrators involved in leadership decisions at a small, suburban high school in the Appalachian region. To protect the identity of this school, we designated the pseudonyms: Appalachian High School (AHS) and Appalachian Local School District (ALSD). This paper details the process and transformation we experience as we investigate a state-mandate to add business collaboration to the local public education sphere through the Business Advisory Council (BAC) initiative.

Allison is the BAC Coordinator at ALSD. The BAC is a group of business owners, public sector leaders, community activists, and school district leaders who discuss ways to contribute to the community's vitality as ALSD students seek employment, training, or additional formal education opportunities. She plans the agenda and leads the meetings in

\footnotetext{
${ }^{1}$ Corresponding Author E-mail: cg890018@ohio.edu
} 
accordance with the preexisting structure and expectations the superintendent has placed on these professional gatherings. While many components of leading the BAC seem to be in Allison's leadership domain, there are obstacles and limitations to her goals and transformative vision. Claire attends the BAC as a participant-observer (Glesne, 2016). In Claire's observations and engagement with the group, she actively co-constructs new plans to revamp the current BAC organizational structure, culture, and climate alongside Allison. As we explore these perspectives, we do so using Block's (2018) Community: The Structure of Belonging as a thinking frame that provides a holistic mechanism for community transformation through strengthening the social fabric of a community in the creation of and accountability to a collective future (p. xi). Block's (2018) approach is holistic in that it emphasizes the necessity of matching intention with the "design of the engagement process" (p. xiii). Block's (2018) methodology matches the intention of creating community through engagement practices that build belonging and provides great insight into how we might intentionally reinforce and reflectively restructure the BAC meetings at AHS.

\section{Background of Study}

As of 2017, Ohio law (Ohio Revised Code Section 3313.82) requires school districts to form cross-sector groups to "foster cooperation among schools, businesses and the communities they serve" (Ohio Department of Education \& The Governor's Office of Workforce Transformation [ODE \& OWT], 2017). In part, this Ohio legislature mandate is a response to reports that found recent graduates entering the workforce lack the necessary professional dispositions and other critical skills to perform well as new-hires (Mourshed et al., 2012; Hart Research Associates, 2015). The Ohio Department of Education (ODE) designates that BAC members should "advise, advocate, aid, and support" school districts in the needed employment skills and priorities, so the school district can "ensure the work of education aligns with the needs of businesses" (ODE \& OWT, 2017). BAC groups develop an annual plan for district programming and curriculum consisting of, but not limited to, activities such as job fairs, job shadowing, mentoring, and career counseling (ODE \& OWT, 2017). While the ODE gives clear directions as to the BAC's purpose and activities, local control is given to developing the convening operating style. In the year-old ALSD BAC, the superintendent runs the meetings like a school board meeting, in a formal style using Robert's Rules of Order, known internationally as Parliamentary Procedure, where voting participation is limited to only five board-approved "members" chosen by the superintendent. Other community organization leaders, education leaders, and community activists may attend the BAC meetings, but none of those "guests" have voting power to make decisions.

The ALSD superintendent asked Allison to take over BAC coordination early on, and through her first year as BAC coordinator, Allison identified tensions between BAC meetings' form and purpose. The BAC consists of people who would not normally meet as part of their job descriptions and requires these people to build connectivity between the school and the local business community. However, the meeting format discourages deep connection and collaboration between council members and guests. Although schools are often imagined as open-social systems, responding to environmental forces and composed of interdependent social components (Hoy \& Miskel, 2013; Karmokar, 2019), K-12 schools and school curriculum are infamously understood to be separate from the real-world and real world learning (Beck et. al., 2017; Engel, 2019; Ghoshal, 2019; Wilhelm \& Smith, 2002). Furthermore, the bureaucratic roles and expectations that govern a school as a formal organization leave it unable to adapt quickly to subtle changes in the environment or respond efficiently to other environmental and cultural changes (Smith \& Larimer, 2004). The hierarchical, bureaucratic model in which schools function, while recognizing the professionalism of specialists like teachers, condenses formal, decision-making power into the 
hands of a few administrators, namely the superintendent and the board of education. Nowhere can this concentration of power be seen more clearly than at a meeting governed by Robert's Rules of Order protocol.

By extending the bureaucracy of the school to the BAC, a group meant to breathe new life into the school district's curriculum through relationships and new knowledge of the changing landscape of the market, an infectious sense of rigidity creeps into meetings, robbing the group of the very purpose for which it was intended. The conflict of the intended versus actual purpose sometimes serves to be an obstacle in itself. For instance, observable in the meetings, members choose their words haltingly, apologize for violating or simply not knowing the exact Robert's phrase for a given act. In deciding moments, almost all members equivocate, then side with the superintendent. Ultimately, the power of membership and involvement begins and ends with the superintendent's recommendation. There is little room for imagining or bringing a holistic sense of identity into the meetings, where a love of place and energy for change could be expressed. Instead, a monotony of routine sets in and is followed by an emphasis on product and task without a clear guiding vision.

The purpose of this study is to evaluate the extent to which the operating methodology of the group could be shifted within the existing structure to engage more aliveness (Block, 2018) and build more of a sense of shared accountability for the creation of an alternative future for our community. We believe that the BAC could be leveraged for radical change within the school. The $\mathrm{BAC}$ is unique in that its intended purpose is not to be a traditional interface between the school and outside environment wherein the school has the power and the community has "input" as the case is with board meetings, coffee with principal meetings, the PTA, and even academic boosters.

In many groups where the community is allowed an entry point into the daily proceedings of schools, the school offers a controlled form of participation and no real opportunity for systemic transformation. The BAC, on the other hand, has been formed by state law with the explicit intention to change schools. Therefore, the BAC has the potential to be wielded as a wide-reaching change mechanism. However, Allison, as an emerging school leader, is inheriting a BAC already hampered by the systems which constrain other forms of community participation in schools. Further, the superintendent attends each BAC meeting and has expectations that his operating norms be followed; Allison's job security depends on his approval. Therefore, our study seeks to answer the perennial question: How do emerging transformative leaders negotiate and create meaningful change in a pre-established system where leaders in power have a vested interest in preserving the status quo?

\section{Elements of Block's Community: The Structure of Belonging}

This study assesses the existing BAC meetings through application of Block's (2018) "social architecture of building community" (p. 189). Block posits a model for leadership wherein a leader functions as a connector, creating the invitation for people who would not normally meet to come together in an environment designed to draw out potentials for a new collective future. Further, Block says, "The real task of leadership is to confront people with their freedom," which he says is the "ultimate act of love" (p. 21). Leaders engaged in this task create and inspire awareness of freedom, possibility, and accountability in small groups through reframing through language and questions.

We apply Block's (2018) leadership ideology and elements for creating belonging to assess opportunities for shifting the BAC's current modus operandi to be more aligned with the BAC's purpose. Through this process we realize Block's holistic vision for transformation through group community building. Specifically, this analysis focuses on the following elements of Block's structure and methodology: gifts, associational life, and power; the power of language, context, and possibility; social capital and the well-being of community; aliveness, 
wholeness, and unfolding; paradox, freedom, and accountability; and emergent design. Several of Block's elements relate to the concepts of community transformation which illustrate a shift in thinking about connectedness.

For Block (2018), the building of social fabric through a new mindset is the foundation of meaningful transformation. For this reason, Block (2018) focuses on gifts, associational life, and power through an emphasis on language and context shifting. Block argues that framing the community and its members as problems to be solved traps citizen groups convened for change in a context pattern of deficit, isolation, and blame. However, beginning with a mental model focused on assets and a belief in the power the citizens hold creates opportunities for real change through accountability and relationships. Furthermore, Block's (2018) theoretical approach to possibility emphasizes the need for conversation as an "action step" that shifts the community's narrative by inviting people who would not normally interact to begin creating new stories about the community's future.

Block's (2018) elements of social belonging draws heavily from Putnam's (2015) research which found social capital, the strength and quality of relationships between citizens, defines a community's well-being (Block, 2018). Healthy communities have high bridging social capital - social networks composed of relationships that seek to include and strengthen ties beyond homogenous identity groups (Block, 2018). To strengthen a community's social fabric through increasing Block's concept of bridging social capital, Block (2018) emphasizes the need for every gathering, every step of community building to be transfused with aliveness, wholeness, and unfolding.

Wholeness and aliveness demand that details and interactions that are traditionally jettisoned as inconsequential are given consideration and importance as a living, emerging microcosm of the community's desired future. According to Block (2018), wholeness and unfolding mean that "We have to worry as much about the arrangement of a room as we do about the community issue that caused us to assemble" (p. 20). The means, therefore, are the ends. In addition, appreciating paradox through accepting and inviting dissent as well as reframing and inverting questions allow citizens to choose freedom and accountability. The community's social fabric is created through depth of connection.

Block (2018) asserts that the whole "system" of the community should be invited to the room, then the large group broken into small, diverse groups, putting people in intimate contact with a representation of the whole. Bridging these concepts and Block's (2018) methodology, the small group is emphasized as the driver of change and is a critical tool for transformation. Borrowing from Dick and Emily Axelrod, Block (2018) says of the small group's transformative power: "If we can change the way we meet, we can change the way we live together" (p. 22). Block's (2018) methodology uses enhancing relatedness within a small group as the starting point for systemic change and emergent design. Although creation through learning begins slowly on a small scale at a "grassroots level," from there, it will grow on an exponential curve. This approach to creation values mistakes, play, and appreciation of questions as transformational tools.

We apply Block's (2018) approach to community transformation to the current operation of the small-group BAC, a group whose intended purpose is to create district-wide change through community relationships, but whose operating methodology contradicts the group's purpose and intention. As nascent school leaders engaged in the business of transformation, we analyze their lived experience for opportunities to create change within the existing, inherited BAC system structures. Through applying Block's elements and methodologies to the existing BAC structure, we also experience a shift in our identities as educational leaders.

\section{Research Questions}


The following research questions guide this study:

1. How do emerging transformative leaders negotiate and create meaningful change in a pre-established system where leaders in power have a vested interest in preserving the status quo?

2. To what extent did an existing community-oriented group embody Block's (2018) Community: The Structure of Belonging concepts and methodologies?

3. Where are opportunities for transformation within the pre-existing structure of the BAC?

Through our autoethnographic experiences, we explore their responses as an opportunity to foster their own transformative growth of their educational leadership identities.

\section{Methodology}

This study is a co-constructed auto-ethnography. Ellis et al. (2011) define autoethnography as "an approach to research and writing that seeks to describe and systematically analyze (graphy) personal experience (auto) in order to understand cultural experience (ethno) (Ellis, 2004; Holman Jones, 2005)" (as cited in Ellis et al., 2011, para. 1). This research involves the researchers' lived experience as experiential, reflexive, and informative, which differentiates this form of qualitative research from others (para. 1). This format allows autoethnography to engage in research from a full, descriptive, unique standpoint not entirely achievable with any other qualitative format (para. 5). Furthermore, Spry (2018) describes autoethnography as a way to "conceptualiz[e] the Other for the purpose of understanding self" (p. 630). Thus, in designing a co-constructed autoethnographic narrative, we aim to answer the research questions and explore the depth of their growth through the lived experience of transformative leadership efforts.

According to Spry, it is also clear that "critical reflection is not enough" (p. 631). This form of research must serve a purpose and make a difference. It is important to note that this co-authored autoethnographic paper is not being written as an autobiography or ethnography, but the format begs the fusion of these two approaches (Ellis et al., 2011). This enables us to engage in meaningful and intentional reflexivity. In congruence with the recommendations of Miles et al. (2014), we synthesize the information into a co-constructed narrative by "noting patterns [and] themes," "seeing plausibility," "clustering," "making metaphors," "counting" the data to "see "what's there," and "making contrasts/comparisons" (p. 277). The co-authored narratives are limited through the research questions for the purpose of self- and systemsimprovement.

\section{Co-Constructed Narratives}

We are experienced educators with a desire to engage in lifelong learning practices for the betterment of the professionals and school-communities around them. Through coconstructed narratives, we engage in "the meanings of relational experiences" (Ellis et al., 2011, para. 24) and our transformative experiences in the context of the research questions. Ellis et al. (2011) describe co-constructed narratives as a form of autoethnography that:

...illustrate the meanings of relational experiences, particularly how people collaboratively cope with the ambiguities, uncertainties, and contradictions of being friends, family, and/or intimate partners. Coconstructed narratives view relationships as jointly-authored, incomplete, and historically situated affairs. Joint activity structures co-constructed research projects. Often told about or around an epiphany, each person first writes her or his experience, and then 
shares and reacts to the story the other wrote at the same time (see Bochner \& Ellis, 1995; Toyosaki \& Pensoneau, 2005; Vande Berg \& Trujillo, 2008 ) (sic). [23]" (as cited in Ellis et al., 2011, para. 24)

This study followed the format described above by Ellis et al. (2011). We each wrote our own narratives and then reacted to each other's narrative in our discussion section. The discussion section is also our analysis section in that we examined the narratives of each participants in relation to one another and Block's (2018) approach. Our identities as educational leaders transform through the process of enacting this alternative framework to the pre-existing BAC structure.

\section{General Process}

The data in this paper was collected through observation (i.e., field notes) and document analysis (i.e., agenda items). The initial step was for Allison to create an agenda as usual and to lead the meeting. During the meeting, Claire acted as a participant-observer while Allison ran the meeting. Both of us noted which of Block's elements organically manifest and which are currently unseen. Following the meeting, we conferred and assessed this initial BAC meeting to identify the potential for supplemental or additional Block influence for future meetings.

This autoethnographic study considers the criteria Miles et al. (2014) description that "Autoethnography examines the self, while duo-ethnography examines the self in relation with another-who is also examining one's self" (p. 8). This strategy requires "analytic choices" to be "made continuously" (p. 8). As such, we take a meaningful approach to qualitative data analysis while preserving the quality and integrity of the research methods, context, and participants. For instance, we have formed clear research questions and ensure that "the features of the study are congruent" (p. 305). Additionally, we provide thick, rich description surrounding "the researcher's role and status within the site" and aim to connect the "basic paradigms and analytic constructs...to theory" (p. 305). The study is bound by the unique perspectives of each auto-ethnographer in this co-constructed paper.

\section{Our Autoethnographic Narratives}

\section{Allison's Observations}

I always forget to ask for the vote. I remember to ask for the motion and the second, which seems so forced that I trip over the words and don't really understand which items need an actual vote and which don't, so I really just improvise in the middle of meetings, and I always forget to ask for the vote. It is not lost on me that this ersatz process of formally voting undermines the organic consensus our discussions normally yield. I can't help but wonder why we put these actions to a formal vote? Is it a show of accountability? If so, to whom exactly? The Robert's Rules of Order functioning makes me feel like an invisible accountability officer looms over the group in space, like the old testament god, here to smite us with his punishment should we misstep in the proceedings.

I am the second-youngest person in the BAC, and yet, I am its "leader." I was appointed by my superintendent to lead the BAC meetings for our district because I have an affinity for authentic learning through community connections in the classroom. As an English teacher, I've sought to design deep learning for my own students through projects that reach authentic audiences, place-based learning, and community participation in my classroom. In recent years, I've expanded my efforts to include the entire school. I was contracted by an outside group to deliver a problem-based learning curriculum that pairs classroom teachers with a local business to develop content-specific, community problems for students to solve. Additionally, I've built 
an internship program at our high school that offers both paid and unpaid internships for students, and I spearhead the teacher-based team that coordinates a conference-style, wholeschool Career Day annual event. Because I've seen first-hand the exponential, positive difference it makes to learning when the external community is involved in the life of the school, I've become a zealot for community participation in our district. The state legislature also recognizes the potential and need for business and community involvement in education, although we will have to be on guard for some of the more nefarious motivations behind these initiatives from lobbyists who seek to turn our area into a skilled sacrifice zone ${ }^{2}$.

In my position as BAC coordinator, it is my job to set the agenda for the meetings, take and record official minutes, and coordinate the efforts of the school for BAC project implementation. My superintendent chose the meeting structure, selected its members, and created bylaws before I was coordinator, and so I operate the council in a manner I would not have chosen if I was the originator of the group. However, I still believe in the power of community connections in education, and I believe the BAC is a key entry point for change within the district.

Before the BAC meeting, Claire and I arrive early to take stock of the place and to look at it through Block's (2018) eyes. The school has only one official room it uses for meetings with people outside the school. It is in the center of the building with no windows or access to natural light, the walls are creamy beige concrete block, and the lights are a deep, stained fluorescent yellow. The walls are mostly bare. On one hangs a touch-screen smart board with wires dangling across the wall to the outlets and internet ports; on another wall, a 1969 watercolor of the school building sits in a broken frame; and on the back wall there is a glass case filled with random objects, falling shelves, and box lids of paperwork or trash - we cannot be certain. White folding tables are arranged in a large square attempting to be a circle, and the green, swivel office chairs line the perimeter of the circle-square. There are not any other options for chairs and tables for the meeting space.

I call the meeting to order, and we complete introductions in the usual style with name and organization affiliation. Then we approve the minutes from last meeting with a formal vote. The first part of the meeting feels rote, robotic, and doesn't afford any real sense of connection between members. The conversations before the meeting are meaningful, but they usually only involve one or two members at a time, and not the whole group. The only official convening of the group is the approval of the minutes from last week, and that is usually done in silence as the members read and review the notes, or just move their eyes over the page, and then offer a one word affirmative to passing the motion. After the meeting minutes, I give a report on the progress of our current project. We decided previously to pilot a small group of twenty at-risk students for a small group mentoring program. There are several pieces the school needed to set in motion so that the small mentoring groups are ready to meet with their business mentors and career exposure guests. The project is quite an undertaking, and although I have "support" from my administration in the form of no interference, the only one arranging the work, communicating internally and externally, scheduling, and coordinating logistics is me with my full-time teaching load and numerous other responsibilities. However, because I want the project to be successful, I project-coordinate to the nth degree.

The report I give to our BAC members as to the progress of our project lasts almost a full 15 minutes of me monologuing and showing various forms and schedules. I ask for

\footnotetext{
2 The term "sacrifice zone" is a place of ecological destruction caused by the extraction industry or other industrial production. Rural places rich in resources needed by urban areas for energy and expansion are considered by many as "sacrifice zones," as the health of the land and its people are sacrificed to feed the needs of elsewhere. The term used here, inserting the word skilled, refers to workforce development practices of industry that indoctrinate or promise local youth and young adult training in "good jobs" in exchange for their health and the health of their community. See Lerner's (2010) Sacrifice Zones: The Front Lines of Toxic Chemical Exposure in the United States.
} 
feedback and questions, receive a few questions, make a few changes on the form, we vote to formally accept the form, and we move on. After the logistical necessities are completed, I need to introduce our next project for consideration. Our superintendent asked me to include "Profiles of a Graduate" or "Portraits of a Graduate" on the BAC agenda. The current ALSD profile of a graduate was made by the District Leadership Team (DLT), a large group of teachers and administrators who represent each of the different school buildings in the district. The superintendent seems very attached to the profile that the DLT came up with, but all the research I've read explains that these profiles are supposed to be community endeavors, created by all stakeholders in a community who have the vitality and the future of the community in mind. The superintendent left out the majority of stakeholders when creating his profile because he only included school district personnel in making the profile, and this lack of community input shows in the final product.

I want the BAC to have the choice whether to participate in the project or not, so I introduce the current document and other examples from other districts, all while posing rewriting the profile of a graduate as one possibility of a next project for our BAC. A very lively discussion arose from this, including all sorts of questions. What is difficult for me as the BAC leader is that I probably have the most dissent in the group about this. For instance, I think the current profile is arduous, with too many points, and little attention given to the actual local community. Furthermore, for this profile to mean something, it needs to have an implementation plan in place by the administration, which, from what I can tell, is lacking. The principal mumbles a few things about changes already happening with the current high school curriculum. With the ideological centering of the community-centered profile of a graduate, more radical change in praxis would be required.

Some of the BAC members bring up questions about what the profile would be used for, what kind of input the superintendent is actually looking for from the BAC - to which the Superintendent answers that he wanted us to "look it over" and "approve it" or "make suggestions." When the BAC members ask me what I thought we would be doing with the profile, I laughed and said that "(My superintendent) wants to do something different with this than I do." The superintendent then encourages me to give my perspective. I told the BAC that essentially I want scrap the whole profile and start over, beginning the process with a discussion about the purpose of school that includes all of the stakeholders who wouldn't normally meet: parents, students, school personnel, the BAC, and more individuals from the community that we all take responsibility for inviting and convening together. In the end, we decided to table the decision to move forward with this project and delay the formal vote which would solidify our plan to move forward.

The projects that the BAC members choose to put into action, such as the small group mentoring project, emphasize Block's (2018) associational life and the building of bridging social capital. Similarly, members do go beyond the advisory and advocacy purpose of the BAC to take accountability for making these projects happen. At the very least, they commit to show up for additional volunteering with the students. However, the power of language is largely neglected. We have not articulated enough the gifts of our county and home, spending too much time instead beginning with problems, defining students in boxes such as "at-risk," and seeing the problem as created by forces independent of ourselves. This is such a hard habit to break, one I've not had near enough practice breaking even for myself, and a habit I'm not sure I can break without explicitly shifting the norms of the group. As a leader, I've felt so locked into learning the formal operating structure of the meetings and proving myself to my superintendent, that I haven't given myself the freedom to act as the sort of leader that Block describes. I have not sought to be a leader who focuses on reframing and asking questions for the group to discuss. While I do return the BAC to vision and the wider possibility of our actions, I rarely ask the questions that would invite the members and BAC guests to articulate that vision for themselves. 
We've spent a lot of time focusing on how to give students "choices," helping them to connect their education to the community and a career pathway, yet according to Block (2018), this view is still too narrow. The BAC has never discussed, beginning with gifts, what we want the future of our entire community to be. We've never spent the time envisioning what a healthy Appalachian community could be in the future. To dwell in possibility, we must speak it, we must first hold in mind the belief of the qualities we seek to create (Block, 2018). As a coordinator, I am afraid I'm doing too much of the "suggesting" of next projects, which is not emergent design. As a young, inexperienced leader, even though my heart is bent toward transformation, I feel immense pressure to make-happen a portfolio of successful initiatives with my hand on the helm, to prove that major transformations are possible. As a young, educational leader just beginning, I feel I am waiting for transformation, waiting to make my move. I think Block would tell me that we have everything we need right now to make transformation happen.

When Claire and I debrief about how to make change within the existing operating structure of the BAC, I find the majority of shifts need to begin with my language and my approach to the traditional Robert's Rules of Order. I need to practice forming and working with questions and language to help shift the context. During the introduction portion of the meetings, I will need to create a question or opportunity for the individuals to bring their wholeness into the room. Instead of only focusing on their professional sphere by asking for titles, I will encourage wholeness in the beginning of the meeting by asking different connecting questions. Furthermore, it will be important for me to shift my idea of what the "coordinator" of the BAC is. Block's (2018) leader is a convenor, not a director: a leader using deep listening, questions, and language to leave space for freedom and accountability.

\section{Claire's Observations}

As an administrative intern, my role is designated through the local university's clinical model of shadowing a mentor. Thus, I participated in the BAC meetings because my principal participated in them. The model of participation that my mentor-principal demonstrated was one of observation and passive support. This administrative support is provided on a casual, asneeded basis. Since this group is not led by the principal, this role is expected of him and me, by proxy. However, because AHS is situated in a small community, my role as participantobserver administrative intern is also compounded by my role as an academic researcher with a desire to apply this knowledge within public education settings. The BAC group is one area I can be a support, sounding board, and influencer in improving the approach that the BAC leader, Allison, takes in facilitating these meetings. To understand the atmosphere of the physical space of these meetings, I must describe the room in which the BAC met. To get to the meeting space, BAC members are greeted by secured double-doors at the front of the school and check in at the office. Then, translucent skylights and fluorescent overhead lights show members down a short hallway to the cafeteria. Just before this gathering place, members turn left into a meeting room called the McClure room.

Overlooking three tables and chairs cast aside in various corners of the room, the eye focuses on three white, foldable picnic tables that create a U-shape and are capped by a long, brown office table in the room's center. Surrounding the table are 14 green, plush chairs that jolt the sitter into a forced recline if the sitter sits into the chair fully. The off-white walls are bare except for an interactive, Clevertouch Plus TV; a permanent coat rack, empty except a handful lonely of hangers; a portrait of a white-haired, well-dressed, European-American, presumably J. Warren McClure, whose plaque hangs at the back of the room between two cumbersome glass display cases resting on a countertop - the rest of the countertop is scattered with miscellaneous office supplies and technology pieces; and a front-view picture of an unlabeled school, presumably Appalachian High School. 
Most recently, I participate as a BAC participant and observer. Specifically, I take notes on the meeting's progress in relation to Block's (2018) guide on community-building. This Parliamentary Procedure-styled meeting - a choice made by the district superintendent, not the person leading the meeting, as I later found out - leaves much to be desired in terms of Block's vision for effective and engaging community collaboration. However, when viewing the meeting through the administrative intern lens, it makes sense why the superintendent would ask that an initiative like the $\mathrm{BAC}$, which is introduced by the state and is not original, grassroots initiative, be run in such a formal manner.

In fact, the superintendent mentions that the BAC is almost strictly a formality in other schools in the district. Despite this rigid approach, at ALSD, the current leader of the group is attempting to breathe new life into the whole concept and has taken up the challenge of turning the tide on BAC effectiveness for ALSD and the surrounding communities. It is important for me, as an intern learning the administrator role, to recognize the difference in formality and effectiveness as well as how to allow passionate teacher-leaders, such as the teacher who leads these meetings, to take the reins when I cannot personally see to all grassroots initiatives.

As a former-teacher, I view this meeting and see the ways in which it is different to work with community members than it is to work with education-trained colleagues. Both parties seem to come into the room wanting what is best for the student, but there is much necessary discussion of what role the school can and should play in human capital development and student-success as the students are invited to define "success" on their own terms. For instance, each BAC council member comes from a different field and with a different lens as to how the public education system in this school - contextualized to AHS in this case - should best prepare workers to be introduced to and eventually join their career field. There is rich ground to mine here, but I wonder if there should be more teacher-businessperson connections to assist in the complete transference of the BAC's goals for student success. Put another way, it is important to view educators like professionals in their own career field alongside these community member leaders. This is not evident from the current members seated around these haphazard tables.

My identities as a local community member and BAC participant intersect. Thus, I am keenly aware of the feel of the room - or at least, I am cognizant of how I feel when I am in the room. As such, while everyone has established group norms and a common goal, those norms and goals seem to exist in a state of constant question. Additionally, there were no reminders of the overall norms and goals of the group other than to discuss the decisions made and agenda items in previous meetings. I would have liked to see the group take on a firmer identity by creating a mission statement, purpose statement, and slogan of sorts to affirm and remind council members why they are there each meeting. This could also serve as a platform on which each member could confidently share their expertise.

There seem to be lulls where the leader is talking or asking pointed questions that elicit few responses where I would love to see more active engagement from the council members themselves. Granted, I think many on the council would simply say that they are being respectful of their peers and listening. However, I also think the meetings would become more fully alive if we break the members down into even smaller groups and facilitated the meeting similar to stations in a classroom or a book club-some physical setting where people can engage with the material instead of adhering to a dry Parliamentary Procedure (i.e., Robert's Rules of Order). As an educational leader who wishes to positively affect students and schoolcommunities, this style of meeting seems to dampen the will to transform and, instead, encourages the will to conform. There is certainly hope in the similar mindsets of the community members and council members in attendance, but I think there would be value in hearing more of their voice in each session. The agenda and accompanying minutes, as I experience them, reflect the democratic nature of the meeting as well as the future innovations to be implemented. 
My experiences as a doctoral student and educational researcher coincide to reflect on the leadership texts I have read, the interviews I have conducted, the literature reviews I have written, and the questions I still have concerning public education in the Appalachian region. This reflection is based on Block's (2018) text concerning community development, specifically, but considering the tightly coupled orientation of this meeting and how it contrasts with the rather-loosely coupled mindset of the educational hierarchy and delineation of tasks in AHS, there is room to explore potential ineffectiveness (Weick, 1976). Not to mention other authors who present different cases of how to effectively lead schools in areas of schoolcommunity connection, improvement of school climate and culture, and leadership dispositions (Burke, 2017; Burke \& Litwin, 1992; Hoy \& Miskel, 2013; Senge, 2018) provide more reasons to explore dynamic leadership strategies in the BAC meetings. Much of the reflection above this section reflects the guidance and logic presented by these and other researchers who seek to understand.

Overall, the BAC seems to be a well-intended initiative that Allison has begun to sculpt and make effective in her school's community. By including community members, education administrators, and career representatives from varying industries, she seems to turn a regional initiative into a grassroots phenomenon. Of course there are aspects that will need to be improved, barriers to destruct or circumvent, and voices to invite to the table, but with the energy and attention that this BAC is getting from an inspired educational leader, I think they are, overall, off to a good start and will hopefully maintain their own enthusiasm and prioritize their availability to watch the initiative grow. A tricky element not detailed above is longevity. I think the barriers and potential limitations could be direct factors in establishing whether the BAC members will continue to be fulfilled by their involvement with ALSD or will begin to put their talents and energies elsewhere in the community. Based on what I have experienced, I am hopeful that the BAC meetings - as they have begun to run now-will spark further life into the initiative and will continue to work for the benefit of the students and future of businesses and industries in the area, creating an effective school system for all.

\section{Discussion}

In our responses to and discussion of our auto-observations of the BAC meeting, we note some salient emerging themes. Ultimately, the discussion of themes leads to a probing into the tension between the purpose of the $\mathrm{BAC}$ as a group designed to enhance connections and the practice of the group which seems to negate and discourage that very purpose. The thematic exploration reveals a multifaceted approach to answering the research questions. Namely, exploring the extent to which an existing community-oriented group embodies a lifestyle of creating belonging and understanding the ways in which emerging transformative leaders seize opportunities for creating change within a pre-established system.

\section{Physical Space Reveals Paradigm}

For Block (2018), physical space is a tangible manifestation of an organization's beliefs and culture. Beyond functionality, room design and arrangement communicate to people in the room the larger organizational values. For example, meetings that take place in an auditorium with a raised stage, one microphone for an individual speaker, and fixed seats which necessitate citizens sit with their backs to one another insinuates passive reception of one prioritized, elevated voice and discourages discussion. Block urges leaders not to dismiss details such as the context of room design and arrangement as trivial. In building community engagement and belonging, Block argues, wholeness must be valued and attention paid to the container of community engagement as an expression of the future. 
The theme of physical space expressing lack, disconnection, and haphazard construction repeats through our observations. Through the descriptions of the physical space, metaphors and imagery of lack reveal an inherent, felt sense of disconnection. The disconnection is especially ironic given that the room which houses the BAC is also home to almost all community-oriented meetings at the school. The process members must undergo to enter the BAC meeting room likewise illustrates impersonal hierarchy. Members must be admitted into the building by proving that they belong, greeted by impersonal checkpoints that gauge and record their importance. Furthermore, the placement of this windowless room, hidden in the back of the building, away from the school's daily operations, insulates a desire to keep the community separate from the life of the school. The room's position additionally implies a lack of clarity about the way in which any decisions or ideas, generated by the group, will affect the organization beyond the room's impermeable walls.

The physical space also reveals a dependence on hierarchy, even when the BAC is purported to be a group designed to give more democratic input into school decisions. The lack of diversity in the room's decor (i.e., wall color, tables) mirrors the lack of inclusion of diverse voices in the meeting's formal proceedings. The room's solitary portrait of a white male is one that recreates and re-enforces the dominant hegemony of the superintendent, high school principals, curriculum director, and special education director who are all also white males. As Block says, "Patriarchal institutions will create physical space that glorifies those who lead them...and they will be indifferent, in the name of cost, to the space dedicated to workers and citizens" (p. 168). The chairs, although nice looking, contain a vicious surprise (i.e., jolt people into a forced recline) should a person's physicality or ideology lean too far away from the group. The chair, and thus the dominant paradigm embodied by its physical manifestation, requires the offending group member to immediately right themselves after suffering embarrassment.

While the theme of preserving hierarchy and isolation also pervades the description of the smaller items in the room (i.e., coat hangers), the most notable recurring images and metaphors point to neglect. The broken, stained, bits of trash and such "scattered" around the room, the chords and wires hanging precariously from the wall to the outlets illustrate a culture of mediocrity where going through the motions and making-do have replaced thoroughness, responsibility, and excellence in craftsmanship. If the space where community meets school personnel is in a state of neglect and disrepair, the clear communication from the administration and school is that the school does not value the community's input, and the community can expect that whatever it does offer the school will be discarded or put on a shelf with some other trash.

Block (2018) states clearly, "The room is the visible expression of today's version of community or lack of it" (p. 160). The ALSD BAC's physical space illustrates a paradigm of control and desire to insulate the school from community participation. Herein lies the basic tension between the purpose of the BAC and the way ALSD leadership has chosen to operate the community group. The operating design restricts (i.e., dampens, dry) the function and purpose of building meaningful connections between the school and business community to change the school's organization and operation. Even details as small as the lights serve as metaphors for the larger process of the BAC: our description draws attention to the fluorescent lights and lack of natural light. This distinction underscores the reliance of the school on artificiality, superficial and cheap motivating forces instead of the energy which comes from making meaning from holistic endeavors.

Block (2018) makes clear that the arrangement of the room and the physical way in which leaders create the conditions for members to occupy the room creates the context for meaningful change: "The task is to rearrange the room to meet our intention to build relatedness, accountability, and commitment...The room needs to express the quality of aliveness and belonging that we wish for the community" (p. 162). Therefore, as new leaders desire to change existing structures, a very tangible, significant way to begin is to change the physical space of 
those structures in ways that express the changes desired. For us, the physical space provides much opportunity for change. To clean up the display cases, add pictures of students, the mountains of the region, or even student artwork, would serve as reminders to the group of why they convene and where their efforts are headed.

Block (2018) advocates for removing tables altogether to remove barriers to connection (p. 162). He comments in his notes to leaders that by changing the space, people may experience discomfort or disorientation, as the status quo is physically disrupted. This radical approach to creating connection pushes people to the edge of their comfort zones, which is the precipice of meaningful change (Garmston \& Wellman, 1995; John-Steiner \& Mahn, 1996; McDaniel, 1997). By physically transforming the area through our attention and thoroughness, we can hope to begin the process of change throughout the system itself.

\section{Inheritance of Leadership}

An important set of polarities related to leadership identity are revealed in answer to the research question seeking to investigate the ways in which an emerging educational leader might make transformative change while in the midst of a system that values transactional leaders and dutiful managers. Through our observations, we realize authenticity proved impossible for us as leaders inheriting a system incongruous with our deepest desires for change and social justice reform. The degree to which we conformed to the rigid operating structure (i.e., Robert's Rules of Order) was in direct proportion to the degree of disconnection we felt from the community group we were trying to coordinate.

We are gaining internship experience in the same district in which they held these independent leadership opportunities. We both experienced indoctrination of the system from the same principal who served as the mentor. Similarly, we describe our experience within the education system's culture and definition of leadership as support in the form of lack: a lack of interference and a lack of providing resources or connections to support task management. This same culture also prioritizes formality and standardization as a way to increase effectiveness. Under a formal system where participants are forced to adhere to rules and norms crafted by a distant and unrelated third party, accountability and power shifts from the collective will of the group to the one person (supposedly the leader) who holds the most knowledge of the rules. The operating structure thus takes on an element of invisible jurisdiction governing the group's behaviors. The leader's formal role as facilitator, we found, meant enforcing pre-established practices.

We share an internal sense of identity as transformative leaders critical of and attentive to unjust power structures. However, as new leaders, the dissonance between this internal sense of identity and the leadership role the superintendent passed on creates a sense of imposter syndrome and insecurity despite a laundry list of previous accomplishments and accolades. Furthermore, we acknowledge the possibility that we face additional complications as the only two women in emerging positions of power where our supervisors are all male. These additional pressures and added intersectionality of leadership identity make the task of navigating the gulf between personal ideology and pre-determined leadership role even more arduous. Wanting to succeed as new leaders, we face additional pressure to conform to traditional ideas of what success as a leader looks like. Block (2018) defines these traditional, patriarchal leadership ideas as hierarchical, "Leaders and top are essential;" directorial, "The task of the leader is to define the destination and the blueprint to get there," and enforcers, "Leaders provide for the oversight, measurement, and training needed (as defined by leaders)" (p. 91). The effect of conforming to an inherited technique out of alignment with personal ideology proves damaging to the group in that the robotic execution of meeting agenda items and restriction of participation served to disconnect the group's leader from the members. 
Not only does the inherited operating structure limit the connection of the leader to the group's members but also repeatedly noted is the member's lack of connection to one another. The formal operational structure as it was modeled for and inherited by the leader affords no opportunity for authentic norm creation or larger visioning. Moreover, the formal operating structure dictates who is allowed to speak and when, restricting diversity of voices and censoring content that strays from listed agenda items. Dynamic approaches to leadership which allow the leader flexibility to frame questions, invite dissent, or even criticize the system of which she leads are not organically possible under the current operating procedures of the BAC.

For Block (2018), leaders who impose rigid operating systems on groups are expressing their sincere desire to dampen participation and maintain their position of power at the top of the hierarchy. On the other hand, Block's version of leadership is rooted in transformation. Leaders convene and create the space where belonging arises from engagement and conversation. The leader invites everyone to focus on the well-being of the whole and makes that purpose explicit in all meetings. Further, instead of facilitating and enforcing, Block puts listening as a primary task of a leader wishing to strengthen the community. Block indicts traditional meeting structures as places that "consume" energy rather than producing it (p. 91). By circumscribing participation and dissent, diversity and aliveness cannot find their foothold, and thus, the productive energy of change dissipates.

Block (2018) provides alternative "Operating Guidelines" for leaders wanting to use community groups for building social capital and creating change (p. 190). Completely opposite of the traditional Robert's Rules of Order, Block's operating guidelines include frames of mind that leaders inhabit when designing meetings. Whereas Robert's Rules of Order provides a script of exact phrases and actions for leaders to follow, Block establishes only foundational operating principles such as:

\begin{abstract}
Social capital is created one room at a time, the one we are in at the moment. The key to a new future is to focus on gifts, on associational life, and on the insight that all transformation occurs through language. Each step has to embody a quality of aliveness, and strategy evolves in an organic way. The essence of creating an alternative future comes from citizen-to-citizen engagement that constantly focuses on the wellbeing of the whole. (p. 190)
\end{abstract}

Block's (2018) principles seem antithetical to Robert's Rules of Order and balancing a radical change structure of the meetings against the expectations of the supervisor seems too risky for a new leader.

Seizing on opportunities to generate diverse voices and prioritize dissent, the BAC group leader can include vague agenda items and plan to ask more questions. Moreover, the group leader can make a priority of eliciting multiple viewpoints and debate as practice of consensus building toward the traditional vote. One element emerging from our study is that power can be derived in articulating the tensions between leadership identity and inherited leadership practices. The analytic process of struggling to understand the BAC's failure to engage its members with internal desires for using the community group for school change led to clear labeling of the forces at play. With those forces clearly named and understood, opportunities for change and choice within the system became more visible. The practice of systemically subverting or altering systems is facilitated by a conscious awareness of the competing forces on a leader's emerging sense of identity and practice. 


\section{“Authentic" Community Engagement}

As a general observation, the right words are written down in policy, but can be neglected, which is an issue in practice. The problem emerges when the "right words" are implemented using methods that clearly contradict or constrain the meaning and purpose of the policy. This approach is the frustrating gap in educational administration and educational leadership, and it manifests in our prevailing observations. As emerging educational leaders, we must work with existing administration tactics that no longer serve an effective purpose in the policy or goals of groups such as the ALSD BAC. We experience the truth in how approaching the BAC, a top-down policy initiative, as a bureaucratic process results in ineffective policy implementation due to lack of connection. Put another way, a policy that looks good on paper must also be implemented with intention, consideration, and reflexivity to see growth and fulfill its genuine purpose. In many instances, policies read as though they will work seamlessly; however, implementation for mere compliance has the power to undo all good intentions. This difference in outsider/insider understanding was a topic of comparison within our reflections. All BAC stakeholders, even external constituents such as researchers and guests, should be able to walk into each meeting and be able to follow along. This element represents a gap in awareness of the leadership in giving this meeting, holistically, to the members and guests as invaluable participants in the school-community.

The notion of desire for authentic grassroots leadership was a prevailing and recurrent theme since there appeared to be a notable lack in empowerment. The BAC members claim limited vocal real estate in the meeting discussion. This inhibits the ability for bonds to form between and among all participants in the BAC initiative. Considering the way in which the physical space informs and reveals the paradigms present in this meeting also provides insight into the inheritance of leadership from one person in a position of power to the next. This, in turn, aligns with the ability for all individuals to connect with one another.

As educational administrative leaders, we communicate a struggle to connect the BAC community members to one another, the purpose and vision of the group, and to the leader(s) in the room. As an aside, Claire mentions the possibility of more than one leader because of the chain of command that is present within the room at the meeting: the BAC leader (i.e., Allison), the school building principal, and the district leader (i.e., the superintendent). At any point in the meeting, the principal and/or superintendent has implicit power and opportunity to step in and guide components of the meeting. At times, it seems that participants in the meeting complacently defer to this hierarchy. This problematic system of power "inheritance" leaves the designated BAC leader with a false sense of ownership. Additionally, the template the meeting must follow (i.e., Robert's Rules of Order), as designated by the superintendent, not the BAC leader, is used to guide individuals through shallow proceedings. All of these elements undermine any opportunities for authentic connection, wholeness, freedom, and accountability of the group itself.

A clear sense of inauthenticity results directly from the community's lack of connectivity. In a sense, to attempt to run a meeting with attention to wholeness and a willingness to be captivated by the voice, expertise, and confidence of the BAC members is lacking. As such, there is a clear lack of connection and a clear inability to authentically engage in both Robert's Rules of Order and the BAC's true goal in mining the community for resources, expertise, and synergy to inspire reciprocal vitality within the school-community and community-school sectors. The polarity in the meetings' directions causes a lack of member control and therefore, ownership over the goals, successes, and failures of the group. The ability of leaders to support the group without overtaking or interrupting progress is essential to encourage members' self- and collective efficacy (Bandura, 1997; Bandura, 2009). Looking to the members and understanding how to give the mission to the group and trust the members to build it is important. This notion, in particular, seems to be confused in the administrative 
procedures of this pre-established organizational structure. For instance, instead of drawing lines of leadership between the hierarchical positions of power sitting among the members and designating what the leader will do and what the members will do, it is advisable to employ a sense of shared responsibility, resources, and inquisitiveness in the facilitation of the mission and vision of this community of people.

Drawing lines and supporting the group by not interrupting it harbors a sense of disengagement and neglect. When a leader asks pointed questions that are met with silence, as was noted in both observations, there is an evident ineffectiveness in leadership technique that has potential to cause an effect for the sense of productivity and fulfillment for all involved. Finally, the explicit distrust of the organizational system is problematic for effective and fruitful meeting sessions. These issues, among others, must be addressed-honestly and wholly-if a new foundation is to be poured for the connection and future hope for this BAC community. Only then will the BAC leader(s) begin to see authenticity and full engagement with and of the BAC members and guests.

A final metaphor within the observations involves the BAC creation and emerging leadership design as hope for the future. A recurring desire for renewal and revival was evident throughout both reflections. The sense of aliveness and the necessity to change the structure of the meetings to become more alive is a pit that can and must be continually filled from meeting to meeting. We express a craving for realistic, actionable steps for change that can be facilitated in small ways in each meeting. This hunger sparks from the well of good-intentions and a desire for the council members to engage in authentic education for the benefit of all, which is simply not currently reality. Despite the meeting's shortcomings, we express hope that room for growth will be understood and fulfilled as the council meets in the future and through increased application, in small ways, of Block's framework. Although there are obstacles, there are also opportunities. As Block puts it, "The argument [just] needs reframing" (p. 177).

\section{Conclusion}

In conclusion, the three emergent themes present our final reflections on the answers to our research questions: physical space reveals paradigm, inheritance of leadership, and "authentic" community engagement. Regarding our first research question, we found the first step for emerging transformative leaders negotiating and creating meaningful change in a preestablished system is to articulate the crossroads of leadership identity and emergent practice. It is important for educational leaders to acknowledge and analyze this felt tension to be transformative. Additionally, educational leaders must embed themselves within the community and cultivate authentic membership amongst diverse community stakeholders as a method of connectivity, conversation, and persistent, sustainable transformation between individuals, entities, and school-community/community-school relations. Regarding our second research question, this existing BAC group embodies Block's (2018) Community: The Structure of Belonging concepts and methodologies to a limited extent although the desire, effort, and capacity for growth is certainly present. Regarding our third research question, we found that there are opportunities for transformation within the pre-existing structure of the BAC to commit to the tenants of Block's (2018) of creating wholeness, empowerment, and collaboration within this group of educational stakeholders. Further, as Block (2018) advises, immediate attention paid to the physical meeting room's aesthetic and design is both an important physical and metaphoric place for emergent leaders to make initial change.

While the COVID-19 crisis complicates the application of Block's (2018) elements in the, virtual, BAC meeting at AHS, it also provides a great opportunity for transitioning the group's structure to transformation at a greater speed than previously possible. In other words, the onset of COVID-19 has, in some ways, shattered the foundation set before us. This makes 
room for emergent design and ongoing opportunity for forward progress toward connected, thriving school-community and community-school engagement at the local level.

\section{References}

Bandura, A. (1997). Self-efficacy: The exercise of control. W. H. Freeman and Company.

Bandura, A. (2009). Cultivate self-efficacy for personal and organizational effectiveness. In E. A. Locke (Ed..). Handbook of principles of organizational behavior. (179-200).

Beck, V. S., King, K. N., Boys, S. K., \& Haas, H. J. (2017). How do you use experiential learning to bridge the classroom and the real world? New Directions for Teaching and Learning, 2017(151), 97-115. Retrieved from https://doiorg.proxy.library.ohio.edu/10.1002/ tl.20251

Block, P. (2018). Community: The structure of belonging. Berrett-Koehler Publishers. Burke, W. W. (2017). Organization change: Theory and practice, 222-244. Sage Publications.

Burke, W. W. \& Litwin, G. H. (1992). A causal model of organisation performance and change, Journal of Management, 18(3), 523-545. Retrieved from https://www.exeter.ac.uk/media/universityofexeter/humanresources/documents/learnin gdevelopment/understanding_drivers_for_change.pdf

Karmokar, S. (2019). Community Capacity Building: The Role of Design in Entrepreneurship. Journal of Ethnic and Cultural Studies,6(1), 162-173. http://dx.doi.org/10.29333/ejecs/231

Ellis, C., Adams, T. E., \& Bochner, A. P. (2011). Autoethnography: An overview. Historical Social Research/Historische Sozialforschung. 12(1), 273-290.

Engel, R. (2019). A bridge from fools: Using the motley fool money podcast to link classroom concepts to real world relevance. Journal of Applied Business \& Economics, 21(8), 2531. https://doi-org.proxy.library.ohio.edu/10.33423/jabe.v21i8.2586

Garmston, R., \& Wellman, B. (1995). Adaptive schools in a quantum universe. Educational Leadership, 52(7), 6-12. Retrieved from https://search-ebscohost-com. proxy.library.ohio.edu/login.aspx?direct=true $\& d b=f 5 h \& A N=9505023468 \&$ site $=e d s-$ live\&scope $=$ site Glesne, C. (2016). Becoming qualitative researchers: An introduction (5th ed.). Pearson.

Ghoshal, R. (2019). Call your representatives: Connecting classroom learning to real-world policy action. Teaching Sociology, 47(1), 51-58. https://doi-org.proxy.library.ohio.edu/ 10.1177/0092055X18792608

Hart Research Associates. (2015). Falling short? College learning and career success. Association of American Colleges and Universities. Retrieved from https://www.aacu.org/leap/public-opinion-research/2015-survey-results

Hoy, W., \& Miskel, C. G. (2013). Educational administration. Theory, research and practice (9th ed.). McGraw Hill.

John-Steiner, V., \& Mahn, H. (1996). Sociocultural approaches to learning and development: A Vygotskian framework. Educational psychologist, 31(3-4), 191-206.

Lerner, S. (2012). Sacrifice Zones: The Front Lines of Toxic Chemical Exposure in the United States. MIT Press.

McDaniel, R. R. (1997). Strategic leadership: A view from quantum and chaos theories. Health Care Management Review, 22(1), 21-37.

Miles, M. B., Huberman, A. M., \& Saldana, J. (2014). Qualitative Data Analysis: A Methods Sourcebook (3rd ed.). Sage Publications.

Mourshed, M., Farrell, D., \& Barton, D. (2012). Education to employment: Designing a system that works. McKinsey Center for Government. Retrieved from https://www.mckinseyonsociety.com/education-to-employment 
Ohio Department of Education \& The Governor's Office of Workforce Transformation. (2017). Business Advisory Councils in Ohio Schools. Ohio Department of Education. Retrieved from https://education.ohio.gov/getattachment/Topics/Operating-Standards/BusinessAdvisory-Council-Operating-Standards.pdf.aspx?lang=en-US

Putnam, R. P. (2015). Our Kids: The American dream in crisis. New York: Simon \& Schuster. Senge, P. (2018). The Systems Thinker, \& Leverage Networks, Inc. Retrieved from https://thesystemsthinker.com/author/peter-senge/.

Spry, T. (2018). Autoethnography and the other: Performative embodiment and a bid for utopia. 627-649. In Denzin, N. K., \& Lincoln, Y. S. (Eds.). The SAGE Handbook of Qualitative Research (5th ed.). SAGE Publications.

Smith, K. B., \& Larimer, C. W. (2004). A mixed relationship: Bureaucracy and school performance. Public Administration Review, 64(6), 728-736. Retrieved from https://doi-org.proxy.library.ohio.edu/10.1111/j.1540-6210.2004.00419.x

Weick, K. (1976). Educational organizations as loosely coupled systems. Administrative Science Quarterly. 21:1-9.

Wilhelm, J. D. \& Smith, M. W. (2002). Reading don't fix no chevy's. Heinemann.

\section{Notes on Contributors}

Claire K. G. Ramsey, previously a high school English teacher and library media specialist, earned her BA in English and a MA in Secondary Education at West Virginia University and is currently an Ohio University (OU) Educational Leadership Doctoral Candidate. At OU, Claire is also an advisor for the Office of Diversity and Inclusion and a public-school administrative intern. In addition to her experience in the US, Claire has teaching, volunteer, and research experience in Bolivia, France, Germany, and Kenya. She is interested in expanding educational research opportunities concerning rural sustainability, the Appalachian region, and comparative, international educational leadership.

Allison L. Ricket works for Building Bridges to Careers (BB2C), a nonprofit dedicated to building relationships across community sectors. Currently, she is the Director of BB2C's BECAN initiative, an effort to spread Community and Career Connected Learning across Appalachia. She coaches leaders to build efficacy and capacity in programming. Allison also trains teachers in pedagogy involving local businesses in the classroom. Allison worked in public schools in Appalachia for thirteen years previously as a high school English teacher. In her work at Ohio University in Educational Leadership, she researches Social Return on Investment and asset-based approaches to rural community building.

Manuscript received September 18, 2020

Final revision received December 14, 19, 2020

Accepted December 23, 2020 